\title{
DE METALENGUAJE DE DISCURSO A UNIDADES LÉXICAS DE LA LENGUA: UN PROCEDIMIENTO DE CREACIÓN LÉXICA DESATENDIDO
}

\author{
Manuel Casado Velarde \\ Universidad de Navarra
}

\section{RESUMEN}

El presente artículo se propone estudiar un procedimiento de creación léxica completamente desatendido en español. Me refiero al proceso según el cual una o varias unidades lingüísticas, utilizadas metalingüísticamente (es decir, mencionadas) en el discurso, han pasado a ser nuevas clases léxicas (sustantivos, adjetivos, verbos, adverbios) en el sistema de la lengua. Realizo una caracterización general del fenómeno -que ha tenido y tiene un notable impacto en la lengua-, así como una propuesta de clasificación de los deautónimos del español.

Palabras clave: Metalenguaje, discurso, creación léxica, autonimia, deautonimia, español.

\section{ABSTRACT}

This paper aims to study a procedure for the creation of words in Spanish that has, until now, largely been ignored. I refer to the process by which one or more linguistic units, metalinguistically employed (i.e. mentioned) in speech, have become new lexical classes (nouns, verbs, adjectives, adverbs) in the language system. I undertake a general characterization of the phenomenon -which has had, and continues to have a remarkable impact on the Spanish language-, as well as a proposal for the classification of Spanish de-autonyms.

Key Words: Metalanguage, discourse, word formation, autonymy, de-autonymy, Spanish.

\section{INTRODUCCIÓN}

Para tratar de asenderear la maraña de lo metalingüístico, considero oportuno partir de algunas distinciones. La triple distinción coseriana de niveles en el lenguaje (universal, histórico e individual) puede ser útil por realista, por amplia y por exhaustiva. De esta manera, cabe referirse al metalenguaje ${ }^{1}$ en otros tantos planos.

\footnotetext{
1 Sigo en este planteamiento a Loureda Lamas 2001 y en prensa.
} 
Podemos hablar, en primer lugar, de metalenguaje en el nivel universal, en el sentido de una propiedad del lenguaje mismo, no de las lenguas o del discurso. En este nivel se inscribe la posibilidad del uso metalingüístico del lenguaje primario (y también del metalenguaje de lengua), lo que representa una propiedad universal del lenguaje en general y que, en sí misma, no puede vincularse a las lenguas históricas $^{2}$. Bien es cierto que su funcionamiento puede estar (y de hecho normalmente lo está) en parte determinado por la gramática de las lenguas ${ }^{3}$. En cuanto que representa una posibilidad universal, esta propiedad metalingüística general se fundamenta en el principio de la «efabilidad» (o la «no inefabilidad») (Gutiérrez Ordóñez 1997, p. 380). Y dado que con el lenguaje puede hablarse de todo, cualquier elemento del lenguaje primario (en cuanto «cosa» o parte de la realidad) puede convertirse («reflexivamente», se dice a menudo) en objeto del decir.

Se trata del «especial uso que las palabras -o cualquier otro elemento del lenguaje primario o de la propia metalengua- tienen de representarse a sí mismas, como es el caso de, por ejemplo, Casa tiene cuatro letras, Juan es un nombre corriente, Palabra se escribe con b» (Porto Dapena 1999-2000, p. 129), donde «casa», «Juan» y el vocablo metalingüístico «palabra» aparecen como unidades citadas ${ }^{4}$, no en su uso normal, es decir, en el relativo a expresiones del lenguaje primario del tipo mi casa tiene cuatro ventanas, Juan es un hombre corriente. Remiten al mismo fenómeno la distinción medieval entre suppositio materialis y suppositio formalis, o la establecida por los lógicos entre «mención»/ «uso», «lenguaje-objeto»/ «metalenguaje», o lingüistas («lenguaje primario»/ «metalenguaje», Coseriu 1977, pp. 107-108).

Pues bien, esta propiedad universal de referirse a un segmento lingüístico que a la vez que elemento lingüístico es una parte de la realidad misma (un hecho material) es una característica que se comprueba en el discurso: se trata del «metalenguaje de discurso» (por oposición al «metalenguaje de lengua o metalengua»: p. ej., palabra, nombre, adverbio, decir, hablar..., cf. infra), en virtud del cual «cualquier elemento lingüístico, sea o no léxico, pertenezca al lenguaje hablado o escrito, puede utilizarse como representante [como «icono» ${ }^{5}$, diría yo] de sí mismo, esto es, metalingüísticamente» (Porto Dapena 1999-2000, pp. 129-130).

\footnotetext{
${ }^{2}$ En la concepción de Coseriu 1987, p. 155ss., se trata de un «universal esencial».

${ }^{3}$ Sobre la gramática y las propiedades de las unidades usadas metalingüísticamente en español, véase Gutiérrez Ordóñez 1997, Castillo Peña 1998, 2001 y 2005 y Loureda Lamas 2006; en francés, Rey-Debove 1997; y en alemán, Ulrich 1997.

${ }^{4}$ Las unidades entrecomilladas en esta oración reciben también otros nombres, como segmentos «mencionados» $\mathrm{o}$ «usados metalingüísticamente» (o también «autónimos»).

5 Debo la sugerencia de la palabra «icono», para designar lo que otros llaman «autónimo», al Prof. de Griego José B. Torres.
} 
Constituye una posibilidad que es universal en su extensión (Loureda Lamas en prensa), como puede observarse en los ejemplos que siguen:

- segmentos superiores a la palabra:

(1) Ese pensé que no vendrías suena a excusa;

- segmentos inferiores a la palabra, como constituyentes léxicos:

(2) El sufijo -ismo forma sustantivos que suelen significar doctrinas, etc.;

- agrupación de letras:

(3) Has puesto tir en lugar de gir;

- sonidos o fonemas:

(4) La /o/ no se pronuncia tan abierta en español;

- letras:

(5) Esa $m$ debería ir con mayúscula;

- signos gráficos:

(6) El signo ; de interrogación;

- unidades o segmentos de otras lenguas:

(7) Springsteen, bardo del yes, we can (titular, El País digital, 27.1.09);

- e incluso fragmentos de una «lengua histórica inexistente»:

(8) Estuvimos cantando el In noreni per ipe, / in noreni cora de La conquista del paraíso, de Vangelis.

Las unidades usadas metalingüísticamente en el discurso constituyen meras formas, hechos físicos, sustancia carente de significado; "no tienen sinonimia ni traducción», escribe Rey-Debove 1978, p. 321; se trata de elementos que no constituyen «ninguna estructura paradigmática» (Porto Dapena 1999-2000, p. 130);

carecen de dimensión simbólica, de manera que no pueden equipararse al contenido de cualquier otra unidad lingüística [...]. Y al no poseer significado, no son nombres de clase (= que dicen que tal o cual elemento designado en la realidad pertenece a una clase conceptual dada), sino que cada unidad mencionada es en sí misma un ente separado e individual (Loureda Lamas 2006, p. 149). 
Tampoco se puede decir que designen: «están» meramente en el hablar. Y, como tales formas, no pertenecen a categoría verbal alguna, es decir, en sentido estricto no son sustantivos, sino unidades con «sustantividad» (Loureda Lamas en prensa) ${ }^{6}$. Tienen un carácter icónico. De ahí mi resistencia a denominarlas unidades «autónimas» o simplemente «autónimos». Si utilizo este término es porque resulta práctico, pero no asumo el concepto que tiene de él Rey-Debove 1978, pp. 28ss), para quien los «autónimos» son homónimos de las correspondientes unidades de la lengua que se usa: una especie de léxico metalingüístico paralelo ${ }^{7}$.

Pero además de ese «uso metalingüístico» mediante el que es dado al hablante utilizar cualquier segmento lingüístico como representante de sí mismo (o sea, del segmento mismo como objeto de la realidad), existen también los enunciados metalingüísticos o enunciados en los que se dice algo sobre el lenguaje (el discurso metalingüístico) en cualquiera de sus aspectos. Por ejemplo, los enunciados de (9) constituyen discurso metalingüístico:

(9) Cuando una persona habla mucho, tiene más riesgo de equivocarse. En cada lugar se habla de manera diferente.

Muy a menudo, en efecto, el hablante se convierte en «lingüista»y valora algún hecho lingüístico, es decir, habla de su lenguaje o del de los demás (Loureda Lamas 1999 y en prensa; Kabatek 2000, p. 61). Se trata, a veces, de intervenciones conscientes en el cambio lingüístico, como la que supone, por ejemplo, justificar o prescribir la moción de género -o/- $a$, al referirse a personas de uno y otro sexo, en lugar de emplear el no marcado (masculino).

Pero además de lo que pudiéramos llamar «discurso metalingüístico libre» (9), también existe el «discurso metalingüístico repetido»de los refranes y proverbios referidos al lenguaje; p. ej.:

(10) Quien mucho habla, mucho yerra.

En cada villa, su maravilla, y en cada lugar, su modo de hablar,

${ }^{6}$ Coseriu 1977, p. 107 afirma: «Todo elemento significante del lenguaje primario (una palabra, una parte de una palabra, una expresión entera) puede convertirse en nombre de sí mismo -y, por consiguiente, en «sustantivo»- en el plano del metalenguaje («verde es un adjetivo», «un si», «-mos es una desinencia», «-mente es un sufijo», «la b», «este creemos que... no me gusta», etc.). Asimismo, el sí y el no son los nombres en metalenguaje de las expresiones sí y no del lenguaje primario. Se trata, en todos estos casos, del metalenguaje del discurso, es decir, del empleo metalingüístico del lenguaje.»

7 Para una crítica del concepto de «autonimia», cf. Lara 2001 y 2002, para quien lo que otros autores llaman «autonimia» es solamente la mención de un signo que se hace en el discurso. «Cuando se menciona el signo se llama la atención sobre él mismo: se vuelve objeto reflejado» (Lara 2002, p. 155; cursiva del autor). 
discursos que manifiestan determinadas valoraciones y actitudes que forman parte de la experiencia colectiva de una particular comunidad, y reflejan normas intuitivamente fijadas sobre el hablar y el lenguaje que son atribuibles a una tradición lingüística o tradicionalidad discursiva (Loureda Lamas 2007).

Otro conjunto de hechos metalingüísticos (en la medida en que «lingüístico» engloba lenguaje y lengua) pertenece al nivel histórico o de la metalengua (o metalenguaje de lengua). Las lenguas, en efecto, disponen de unidades mediante las cuales presentan el lenguaje como «conocido» (cf. Dimter 1981, Wierzbicka 1987, Escobedo Rodríguez 1992, Loureda Lamas 2003a). En español, por ejemplo, hay voces comunes -excluyo, de entrada, todo lo terminológico- que significan:

- formas de hablar, como aconsejar, acusar, conversar, decir, declarar, discutir, mentir, vituperar, etc. (Loureda Lamas 2003b).

- tipos de textos, como apunte, arenga, aviso, carta, charla, comentario, conversación, prólogo, receta, etc. (Loureda Lamas 2003a y 2005, González Ruiz y Loureda Lamas 2005, p. 361).

- modos de realizar los actos de habla, presentes en adverbios y locuciones como francamente, lisa y llanamente, sinceramente (González Ruiz 2000, Aznárez Mauleón y González Ruiz 2006).

- cualidades de las personas en tanto que hablantes, como bienhablado, charlatán, deslenguado, dicharachero, locuaz, mordaz, etc. (Loureda Lamas 1999).

- valoraciones (adjetivas) de los discursos como tales: por ejemplo, conciso, escueto, lapidario, sucinto (Loureda Lamas 1999).

- polifonía discursiva: cita, doblaje, sedicente, etc. (Casado Velarde 2008a).

- etcétera.

Y dentro de la metalengua, pero en el ámbito específico de la fraseología, también existe una serie de unidades que son metalingüísticas (Briz 1998, pp. 199-201).

Encontramos, pues, manifestaciones de lo metalingüístico en los tres niveles fundamentales del lenguaje: universal (la posibilidad de que el lenguaje sea objeto del lenguaje, como en el caso del uso metalingüístico del lenguaje primario), histórico (hechos de metalengua, condicionados en y desde los idiomas, en su léxico -como unidades simples o como fraseología- o en la gramática, ya sea oracional o supraoracional) e individual (hechos de metahabla o, mejor, metadiscursivos: contenidos de discursos -individuales o colectivos y tradicionales- en los que se habla sobre el lenguaje) (Loureda en prensa). Gráficamente (Loureda Lamas en prensa): 


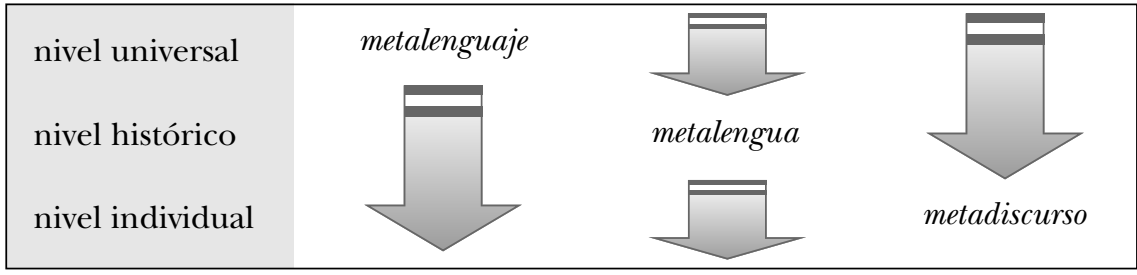

FIGURA 1.

No solo el uso del lenguaje primario hace la lengua, como se admite comúnmente. También la mención o representación icónica que de las piezas lingüísticas se efectúa en el metalenguaje de discurso es responsable de la creación lingüística, como expondré a continuación.

\section{METAlenguaje DE DisCURSO Y CREACIÓN LÉXICA}

El léxico español -al igual que se ha señalado para el del inglés (De Brabanter 2005, p. 171) - debe parte de su riqueza y vitalidad al fenómeno del discurso al que acabo de referirme, consistente en mencionar o citar objetos lingüísticos.

Varios autores llaman «autonimia» ${ }^{8}$, según adelanté, a este fenómeno (De Brabanter 2005, passim; Rey-Debove 1978, etc.). Pues bien, la «mención» o «autonimia» se encuentra en el origen de un número no desdeñable de lexemas del español, que proceden de un segmento lingüístico (grafema, unidad fónica, morfema, una palabra o secuencia) mencionado en el discurso, y no de una mera unidad (llámese raíz, base, tema...) del sistema de la lengua. Se trata de un proceso de formación de palabras («de-autonymy» la llama De Brabanter 2005) desatendido por los lexicólogos (y también por los lexicógrafos), que se han venido ocupando de elementos del sistema de las lenguas, con olvido de los usos discursivos y de su repercusión lexicogenética.

Obsérvense los siguientes enunciados:

(11) Yo distingo entre amigos y conocidos.

(12) Ese distingo es verbo.

(13) Antes de responderte, yo haría un distingo.

\footnotetext{
${ }^{8}$ El término resulta cómodo, pero pienso que no es apropiado: el componente griego óvoua sugiere el contenido de «nombrar», cosa que no ocurre realmente en la mención metalingüística. Como ya dije, los «autónimos» no son verdaderos nombres, sino representaciones o iconos de segmentos lingüísticos en el discurso.
} 
El distingo de (11) pertenece formalmente al paradigma flexivo del verbo distinguir (cuyo tema es disting-: distinguía, -uió, -uirá, etc.); y, semánticamente, al paradigma de diferenciar, discriminar, confundir, etc. El distingo de (12) es una mención (icono, autónimo) del signo distingo (= 'realizo una diferenciación') utilizado como lenguaje primario en (11). El distingo de (13), en cambio, pertenece al paradigma flexivo sustantival - $\varnothing /-s$ (cuyo tema es distingo: distingo, distingos); y, semánticamente, al paradigma de distinción, reparo, restricción, etc. Nos encontramos, pues, ante palabras diferentes.

La incorporación al léxico de esas unidades procedentes del enunciado discursivo se reconoce, entre otras cosas, en la pérdida de su «reflexividad» o carácter «autonímico» (iconicidad) y en su conversión en una nueva clase léxica, como ha podido comprobarse.

A medida que he ido examinando posibles casos de «de-autónimos», he ido comprobando la complejidad que ofrece este fenómeno, de apariencia tan simple en la temprana y cautivadora presentación de Benveniste («Les verbes délocutifs», 1958). Benveniste, como se sabe, llamó «verbos delocutivos» (por analogía con «denominativos» = derivados de nombres) a aquellos verbos cuyo origen hay que buscar no en un lexema de la lengua aisladamente considerado, sino en determinadas fórmulas convencionales. Algunos de los ejemplos que propone Benveniste son los verbos latinos salutare, formado a partir de la fórmula de saludo Salus!, cuyo significado originario sería «saludar diciendo salus», o negare 'decir nec'; o el verbo inglés to welcome 'decir welcome'. El lingüista francés no se interesó, por lo demás, por delocutivos que no fueran verbos.

Pocos autores se han ocupado del impacto del metalenguaje de discurso (la mención o uso metalingüístico) en el léxico. Se pueden citar los nombres de Jespersen 1954, Benveniste 1974 [1958], Rey-Debove 1978, Conte 1984, 1987, Anscombre 1985, Ducrot y Schaeffer 1995, De Brabanter 2005. La cuestión se presta a dos tratamientos principales, uno diacrónico y otro sincrónico. En el primero, indagando si en el origen de un determinado lexema hubo una mención metalingüística, pues como señala Coseriu,

ciertos elementos surgidos en el metalenguaje del discurso pueden ser adoptados en el lenguaje primario y, de este modo, volverse elementos de lengua y entrar en oposiciones semánticas de lengua (Coseriu 1977, p. 108).

En el planteamiento sincrónico, en cambio, atendiendo a si el significado de ese lexema es interpretado por la comunidad de hablantes corrientes en términos de una mención: compárense, p. ej., vitorear (víctor o vítor) o pordiosear y pordiosero (por Dios), con tutear (tú o tu). 
Las discrepancias entre uno y otro planteamiento pueden y suelen producirse, como estamos acostumbrados a comprobar en los estudios sobre la polisemia y la homonimia ${ }^{9}$.

Dejaré de lado la investigación diacrónica, que excede mis competencias. Por otra parte, habrá que esperar en muchos casos los prometedores resultados de los diferentes estudios sobre tradiciones discursivas, hoy en curso de realización.

En la medida en que lo que aquí ofrezco es una aproximación a las posibilidades que presenta el fenómeno en español, dejando caracterizaciones más precisas y pruebas lingüísticas para ulteriores trabajos, me apoyaré en las informaciones que aportan dos diccionarios generales (si bien con diferente alcance diatópico y diastrático): el DRAE 2001 y el DEA 1999.

Obsérvense los ejemplos siguientes:

(14) ¿Cuándo regresas del viaje? (uso del adv. interrogativo cuándo: en qué momento).

(15) Ese cuándo me desconcierta: el problema es cómo (mención de la palabra cuándo).

(16) A mí me interesa el cuándo, no el cómo ni el porqué (lexema cuándo: tiempo),

en donde de nuevo encontramos que, frente al uso primario de cuándo en (14), observamos el empleo metalingüístico, de mención, de cuándo en (15), forma icónica o ecoica de un uso previo formalmente idéntico; y el cuándo en (16), ya sin carácter icónico, sino con la semiosis propia de un signo, de la clase léxica de los sustantivos, con flexión de número y significado «tiempo».

El problema que se nos plantea es cómo mostrar que el cuándo de (16) proviene de una mención discursiva como la de (15) y no del simple adverbio de la lengua que aparece en (14). Los diccionarios, desde luego, salvo alguna excepción, no suelen ofrecer información acerca de la transición del estadio de (14) al estadio de (16). El DRAE, p. ej., en el paréntesis etimológico que sigue al lema, se limita a veces a anotar la voz mencionada («autonímica»): arrear (de arre), azuzar (de sus), pordiosear (de por Dios), parabién (de la fr. para bien sea, que se suele dirigir

\footnotetext{
${ }^{9}$ Por otra parte, con bastante frecuencia no resulta fácil trazar una separación neta entre lo que es un uso puramente metalingüístico (autonímico o de mención) y otro que lo es solo mínimamente (un lexema derivado de una mención discursiva: un «de-autónimo»), como ocurre con unidades lingüísticas que son fórmulas rutinarias (p. ej., un adiós o un gracias), por lo que algunas piezas habrá que catalogarlas unas veces como lexemas de la lengua y otras como menciones (De Brabanter 2005, p. 172). No obstante, en Castillo Peña 2005 se realizan útiles precisiones sobre la gramática de las unidades «autónimas» del español, que podrán servir para deslindarlas de los lexemas nominales de la lengua.
} 
al favorecido con un suceso próspero), etc.; y otras veces, en la propia definición, como en zapear: tr. 'espantar al gato con la voz zape'; ayear: intr. poco usado 'repetir ayes en manifestación de algún sentimiento, pena o dolor'.

Lara 2002, que critica, en mi opinión con acierto, el concepto de «autonimia» de varios autores citados, no logra, en cambio, diferenciar una mención (un «autónimo»), de un sustantivo derivado de ella («deautónimo»). A propósito del enunciado

(17) Esa solución tiene muchos asegunes $^{10}$,

que él mismo pone como ejemplo, y para ilustrar el hecho característico de que las palabras mencionadas se nominalizan en un discurso «reflexivo», afirma:

Asegún (según, en español culto moderno) es una preposición o un adverbio en uso, pero al mencionarlo se vuelve sustantivo. Lo mismo sucede con todos y cada uno de los vocablos de la nomenclatura de un diccionario, pero su significado no desaparece, al grado de que, si uno no sabe el significado de según en español, no entenderá el sentido del dicho popular mexicano (Lara 2002, pp. 155-156; cursivas del autor).

Aquí se hacen, en pocas líneas, afirmaciones de cierto calado, que espero contribuir a matizar a lo largo de este artículo. Nadie duda de que en el texto que sigue se realiza una mención de los posesivos mío y nuestro, en una frase nominal que ocupa el hueco del CD:

(18) En política hay muchos mío y pocos nuestro (La Vanguardia, 19.12.08, p. 80).

Pero esas formas carecen, al menos en el estadio actual de la lengua, del carácter clasificador que proporciona la categoría gramatical de nombre común a formas como los considerandos, los peros, los pagarés o los mentis, aun cuando existan formas que hayan quedado fosilizadas en la fraseología en la función de sustantivos:

(19) Más vale un toma que dos te daré (c. 1549, Hernán Núñez, Refranes o proverbios en romance, Madrid, 2001, CORDE).

En lo que sigue, trataré de agrupar los diferentes resultados que ha producido en el léxico español (actual) el metalenguaje de discurso (es decir, la mención o autonimia).

\footnotetext{
${ }^{10}$ Advierte el autor que «quizá este dicho popular sea sólo mexicano; quiere decir que el asunto considerado presenta muchas dificultades para resolverse» (Lara 2002, p. 152n).
} 
3. CATEgorías de DeRIVAdos de MENCIÓN (O «DE-DisCuRSIVOS», «DE-AUTÓNIMOS»)

\subsection{Sustantivos (o fórmulas sustantivadas) que tienen origen en la expresión con que se efectúan (o efectuaban) determinados actos de habla (delocutivos)}

Existen en español nombres como un adiós, un gracias, un bravo, un hola, un alto, un alto el fuego, un viva, un muera, un hurra, un aúpa, un amén, etc. ${ }^{11}$, resultado de sustantivaciones de expresiones que, por sí solas, constituyen usos completos (lo que algunos autores llaman fórmulas rutinarias -Corpas Pastor 1996, p. 133-). Pueden denominarse sustantivos «delocutivos». Gran parte de las formas en que estas piezas se originan se consideran por lo general interjecciones o fórmulas expresivas con las que se realizan determinados actos de habla, como saludo o despedida, agradecimiento, felicitación, condolencia, aplauso, censura, aquiescencia, petición, prohibición, orden, compromiso, acuse de recibo, desmentido, reconocimiento de culpa, etc. ${ }^{12}$ "Dans les lexèmes délocutifs l'énonciation s'est cristallisée dans le lexique d'une langue» (Conte 1984, p. 67).

Pueden agruparse en varios apartados en función del grado de integración como lexemas sustantivos en la lengua, en un proceso que va desde la (casi) nula pérdida de su entidad de «mención», hasta la (casi) total desaparición de su carácter (metalingüístico o «autonímico»):

a) Constituyen lexemas sustantivos pertenecientes a la lengua española $^{13}$, si bien a diferentes lenguas funcionales, y así se suele reflejar en los diccionarios, voces como: adiós ('despedida', pl. adioses) ${ }^{14}$; alto ('detención, parada', pl. altos); alto el fuego: m. (invariable) 'suspensión de

11 La lengua vasca registra un delocutivo emblemático, el sustantivo doministiku ('estornudo', de Dominus tecum, con conservación de -n-por el prestigio de la lengua litúrgica). La referencia más antigua a formaciones delocutivas que conozco se encuentra en el relato bíblico del Éxodo (16, 15 y 31) acerca del maná: «Al verlo los hijos de Israel se dijeron entre sí: -¿man-hu? (que significa: ‘¿ué es esto?’) Pues no sabían lo que era. Moisés les dijo: -Es el pan que el Señor os da como alimento. [...] La casa de Israel lo llamó maná (en hebreo: man)». Es decir, dan al misterioso alimento el nombre que le habían dado ellos mismos al preguntar qué era aquello. Cuestión diferente es si se trata o no de una etimología popular.

${ }^{12}$ Se trata de la primera de las cuatro subcategorías que, siguiendo a Rey-Debove, distingue De Brabanter, la de los «object-position autonyms», por originarse en la posición objeto de la estructura dire $+x$, en donde $x$ es una mención («autónimo» en la terminología de los citados autores). "This means that dire (or say) is to be taken in the sense of to perform an illocutionary act rather than simply to utter vocal sounds» (De Brabanter 2005, p. 181).

13 También podrían incluirse aquí latinismos crudos como imprimátur, níhil óbstat, plácet, tole tole, etc., registrados en los diccionarios del español.

${ }^{14}$ Ha producido el derivado adiosero - ra adj (raro) 'de despedida o adiós', que registra el DEA, con testimonio de uso: «vibraciones adioseras». 
hostilidades' (DEA); ay (m. 'suspiro, quejido': Tiernos ayes DRAE 2001; PARA ayear, cf. 3.6); parabién (de la fr. para bien sea) m. 'felicitación' (DRAE 2001).

De étimo perteneciente al discurso escrito (texto escrito que dice: $X$ ) provienen sustantivos como:

cargareme: (de cargaré y me) $1 . \mathrm{m}$. documento con que se hace constar el ingreso de alguna cantidad en caja o tesorería (DRAE 2001).

cese: (imper. del verbo cesar) 1. m. acción y efecto de cesar (en un empleo o cargo); 2 . m. nota o documento en el que se consigna el cese de un empleo o cargo. La RAE lo incluye por primera vez en su Diccionario usual en 1791, y lo define como «la nota que se pone en las listas de los que gozan sueldo de la Real Hacienda, particularmente en la Milicia, para que desde aquel día cese el pago del que tenía algún individuo»; y a partir de la edición de 1884, con mínimas modificaciones en la definición, añade en el paréntesis etimológico: «imperativo del verbo cesar»;

cúmplase: (imper. de cumplir): 1. m. decreto que se ponía en el título de los funcionarios públicos para que pudiesen tomar posesión del cargo o destino que se les había conferido; 2. m. fórmula que ponen los presidentes de algunas repúblicas americanas al pie de las leyes cuando se publican (DRAE 2001, s.v.; no lo registra el DEA) ${ }^{15}$

detente: (imper. de detener) 1. m. recorte de tela con la imagen del Corazón de Jesús y la leyenda Detente, bala, que se usó en las guerras españolas de los siglos XIX y XX, prendido en la ropa sobre el pecho (DRAE 2001); lo registra tb. DEA, con testimonio;

mentís: 2. ${ }^{\stackrel{a}{p}}$ pers. de pl. del pres. de indic. de mentir. $1 . \mathrm{m}$. voz injuriosa y denigrante con que se desmiente a alguien. 2. m. Hecho o demostración que contradice o niega categóricamente un aserto. 3 . m. Comunicado en que se desmiente algo públicamente (DRAE 2001; también lo registra DEA);

pagaré: papel de obligación por una cantidad que ha de pagarse a tiempo determinado (DRAE 2001);

pase $^{2}$ : (imper. del verbo pasar, palabra con que, por lo común, empiezan esta clase de documentos) 1 . m. permiso que da una autoridad para usar un privilegio, licencia o gracia (DRAE 1884); en DRAE 2001 figuran, además de la anterior, otras acepciones; tener un pase: 1 . fr. coloq. ser aceptable o tolerable (DRAE 2001) (cf. lo dicho para cese);

recibi: fórmula que, situada delante de la firma en ciertos documentos, expresa que se ha recibido lo que en ellos se indica (DRAE 2001);

renuncio: $1 . \mathrm{m}$. En algunos juegos de naipes, falta que se comete renunciando. 2. m. coloq. Mentira o contradicción en que se coge a alguien (DRAE 2001; también lo registra DEA);

\footnotetext{
${ }_{15}$ En el español de España parece anticuado, pero véase el siguiente testimonio: «La sentencia había sido aprobada en Madrid y se hallaba en su poder con el cúmplase reglamentario» (1983: J. L. Olaizola, La guerra del general Escobar, Barcelona, Planeta, 1990; abundan testimonios de uso en el español de América).
} 
saluda: comunicación escrita breve, no firmada, en que van impresas la indicación del que la envía y la palabra saluda, a continuación de las cuales se escriben el nombre del destinatario y el texto del mensaje; también el impreso correspondiente (DEA);

stop: $\mathrm{m}$. señal de tráfico que indica la obligación de detenerse (DEA); en varios países de Hispanoamérica, pare;

suplico: en el Derecho, súplica (DEA);

visto bueno: fórmula que se pone al pie de algunas certificaciones y otros documentos, etc. (DRAE 2001); etcétera.

Cabe incluir en esta categoría los sustantivos oíslo 'persona querida y estimada, especialmente la mujer respecto del marido' (DRAE 2001 y DEA, literario, raro), pésame 'manifestación de condolencia' y pláceme 'felicitación', el desusado pésete 'especie de juramento, maldición o execración' (DRAE 2001 y CORDE) cuyos étimos hay que buscar en fórmulas ya desaparecidas de expresar, respectivamente, condolencia, felicitación, maldición, así como vítor ('aclamación', pl. vítores).

En Argentina, el sustantivo m. parate 'en el ámbito del comercio, disminución de la actividad' (Chuchuy 2000, s.v.) se documenta ampliamente (solo en CREA encuentro 16 testimonios):

(20) Me tocó la «colimba» en Puerto Belgrano y el parate me apartó de la selección (La Nueva Provincia, Bahía Blanca, Argentina, 08.4.97, CREA).

Y en el área del Río de la Plata, sosegate (del esp. rioplatense sosegate, imper. de sosegar, en uso prnl., m. coloq. Arg., Bol., Par. y Ur.) vale por «reprimenda, de palabra o de obra, con que se corrige a alguien para que no continúe en lo que estaba haciendo o no lo repita»; en Nicaragua, interj. usada para tranquilizar a alguien (DRAE 2001) ${ }^{16}$.

En Ecuador, el sustantivo acude es nombre común: «peón que trabaja en una hacienda a cambio de ciertas ventajas en especie» (Richard 2006, s.v., que cita testimonio):

(21) Estos indios libres, además de ser jornaleros, trabajan también como meseros, acudes o, según los llama el Código de Trabajo, como «yanaperos» o «ayudas» (L. Monsalve Pozo, El Indio. Cuestiones de su vida y de su pasión, p. 408, apud Richard).

La forma «deautónima» enhorabuena (f. 'felicitación', DRAE 2001) aparece en la locución verbal dar la enhorabuena (DEA).

b) Aunque no presenten en la lengua el carácter de sustantivos, en el uso se sustantivan con frecuencia, y así suelen registrarlo los diccio-

\footnotetext{
${ }^{16}$ Agradezco a Pablo Pérez San Millán que me facilitara esta voz.
} 
narios, formas como: ábrete, sésamo ${ }^{17}$, amén, arre, aúpa, bravo, hurra, mea culpa, muera, ole (olé), porvida, viva, así como la expresión sálvese quien pueda ( fórmula con que se indica que cada cual debe actuar pensando en su propia salvación o utilidad. Frec. fig. con intención ponderativa. A veces sustantivada»; cita testimonio: esto es el sálvese quien pueda, DEA, s.v. salvar).

Los diccionarios registran, con dispar caracterización, (el) no va más. Para el DRAE (2001, s.v. ir), el no va más es una loc. sust. m. que significa «lo mejor que puede existir, o imaginarse o desearse». El DEA (s.v. ir) acoge dos unidades: no va más, «en la ruleta: fórmula con que el croupier advierte el fin de las apuestas»; y el no va más, loc. nominal masculina, col. «el máximo de intensidad, de calidad o de importancia», y «tb la persona o cosa que lo representa».

El sustantivo amén tiene un plural regular amenes (cf. el refrán «Muchos amenes al cielo llegan») y forma parte de varias locuciones adverbiales -en un (decir) amén, en un santiamén-.

Por su parte, el latinismo mea culpa ha desarrollado el derivado meaculpismo:

(22) En el balance del año que ha terminado, la BBC hace «meaculpismo» sobre el exceso informativo ofrecido en relación al caso de Madeleine McCann (E. J. Blasco, ABC digital, 17.1.08, CREA).

Aun sin presencia en los diccionarios, la oración Ceda el paso (abreviada en $c e d a$ ) con que se verbaliza ciertas señales de tráfico conoce abundantes usos sustantivados:

(23) Un Seat Ibiza se saltó un ceda el paso y colisionó contra un Mercedes (La Vanguardia, 08.4.94, CREA).

Y algo similar cabría decir de prohibido el paso (no hay testimonios de uso en CREA, pero abundantes en la lengua oral, como refleja una sencilla búsqueda en Google):

(24) De golpe y sin avisar a la población, a la hora de circular te encuentras un stop, un prohibido el paso, calles que antes de una dirección ahora son de otra (<http://pemacu.blogspot.com/2008/10/prohibido-elpaso.html $>$ ).

c) No aparecen en los diccionarios bajo ninguno de los dos criterios anteriores, ni como sustantivos ni como unidades sustantivadas, un conjunto de piezas que los diccionarios, cuando las incluyen, clasifican por

\footnotetext{
17 Para DEA, fórmula oracional (ábrete, sésamo o sésamo, ábrete) usada como fórmula mágica para abrir puertas o superar obstáculos. «Frec. se sustantiva como n. m., a veces en la simple forma sésamo». No figura en DRAE.
} 
lo común como interjecciones, con las que se realizan diversos actos de habla. En los testimonios que siguen podemos observar que las unidades destacadas en cursiva no son «autónimas», iconos, formas concretas previamente dichas, sino representaciones de palabras abstractas:

- gracias:

(25) Pensara lo que pensase, no lo dejaría de hacer ni recibirían nada a cambio de su acto, ni un aplauso ni un reproche ni un gracias $(1980$, J. Benet, Saúl ante Samuel, ed. de J. B., Margerot III, Madrid, Cátedra, 1994, CREA).

- hasta luego:

(26) La despedida en el puerto aéreo fue un hasta luego bañado en lágrimas (1993, C. Bain, El dolor de la Ceiba, Novela, Colombia, México, Edamex, 1995, CREA).

- hola:

(27) Mientras Wilson levantaba la mano en un hola o en un qué hay difuso (1980, P. Vergés, Sólo cenizas hallarás (bolero), República Dominicana, Novela, Barcelona, Destino, 1981, CREA).

- qué hay:

(28) Mientras Wilson levantaba la mano en un hola o en un qué hay difuso (1980, P. Vergés, Sólo cenizas hallarás (bolero), República Dominicana, Novela, Barcelona, Destino, 1981, CREA).

En este último testimonio se comprueba la desvinculación de hola y qué hay con respecto de la estricta mención (o «autonimia»).

- okay:

(29) Sandra soltó un okay de esos que uno normalmente quiere comerse (1981, A. Bryce Echenique, La vida exagerada de Martín Romaña, Novela, Barcelona, Anagrama, 1995, CREA)

- por Dios:

(30) De nada valieron las órdenes flácidas del coronel, de nada valieron los pordioses, ni los violetas-porfavor del coronel Eymar (A. Méndez, Los girasoles ciegos, Madrid, Anagrama, 2004, 76).

- porfavor:

(31) La interrumpí en otra de sus aclaraciones [...] para pedirle el número de su apartamento. Ese mismo, y casi iba a añadir un por favor cuando recordé lo peligroso que puede ser ese extraño extra en La 
Habana (1986, G. Cabrera Infante, La Habana para un infante difunto, Barcelona, Plaza y Janés, 1993, p. 376, CREA, con 3 testimonios más, pero netamente autonímicos).

- $\operatorname{rasca}($ y gana):

(32) El Concello, la Federación Coruñesa de Comercio y las asociaciones de comerciantes firmaron ayer un convenio para poner en marcha a partir de la semana que viene una campaña de promoción del pequeño comercio en la ciudad. Lo más destacado: los «rasca y gana» con cientos de premios que repartirán a sus clientes los establecimientos que participen en la promoción. (ADN, ed. digital, 19.11.08; más aproximadamente 2000 entradas en Google).

(33) Cobrar los rasca [título]. Silvia Vázquez González quiere quejarse porque no ha podido cobrar los cupones de rascar de la ONCE. «Voy acumulando rascas durante una semana y voy a cobrar el dinero (100 euros) que me ha tocado a un puesto de la ONCE y me mandan a la Caixa $[\ldots]$ (El Diario montañés, ed. digital, 18.6.06).

- come y calla:

(34) Y continúan jactándose de lo bien que supieron escoger cuando, entre el pragmatismo silencioso y la quimera combativa, optaron por el come y calla (J. Barril, El País, 01.2.1990, última p.).

- ya vale ${ }^{18}$ : esta forma ha desarrollado el derivado yavalismo:

(35) Uno de los males endémicos de Carpetovetonia fue el «yavalismo». Eso del «ya vale» invadió las almas de este país [...]. El «yavalismo» fue el culpable de la chapuza nacional. Todavía quedan algunos rastros de «yavalismo».

(<http://comunidad.terra.es/forums/4/5032159/ShowThread.aspx $>$ ).

- zape:

(36) El gato barcino es un gato injustamente olvidado. [...] Cuando se acerca a la gente lo hace con lento paso, desconfiado y huraño, porque suelen gritarle un jzape, gato! (F. Henríquez Gratereaux, Disparatario, República Dominicana, Santo Domingo, Alfa y Omega, 2002, CREA).

El zapeo adaptación del inglés zapping se construye con hacer: hacer zapeo o zapear.

La lengua literaria proporciona abundantes ejemplos de neologismos delocutivos:

\footnotetext{
18 En las columnas periodísticas aparecen con frecuencia sustantivaciones de carácter análogo: «Es la política del como sea», la única que Zapatero es capaz de mantener sin alteraciones a lo largo del tiempo» (I. Camacho, «La timba», $A B C$, 24.6.09, p. 11).
} 
(37) He almorzado solo ahora, y no he tenido / madre, ni súplica, ni sírvete, ni agua (C. Vallejo, apud Romero Gualda 1980, p. 147).

(38) ¿Amor? No amor, sino mejor cariño. Eso de amor -decíase Ramiro ahora- sabe a libro; sólo en el teatro y en las novelas se oye el yo te amo; en la vida de carne y sangre y hueso el entrañable ;te quiero! y el más entrañable aún callárselo. [...] Oración ha de ser el comer, y el beber, y el pasearse, y el jugar, y el leer, y el escribir, y el conversar, y hasta el dormir, y rezo todo, y nuestra vida un continuo y mudo «ihágase tu voluntad!»

Las unidades consideradas en este apartado podrían denominarse sustantivos (o fórmulas sustantivadas) «delocutivos» (cf. Benveniste 1974 [1958], quien sólo aplicó a los verbos esta caracterización de «delocutivos»).

A su vez, las unidades que he venido citando (adiós, alto, cese, detente, pagaré, recibí, saluda, etc.), en su uso ilocutivo, provienen de la abreviación de fórmulas rutinarias con las que se expresaban diferentes actos lingüísticos: a Dios te encomiendo; detente, bala; etc. De ahí que algunos autores las llamen «delocutivos formularios» ${ }^{19}$ (Anscombre 1982; SirdarIskandar 1989).

\subsection{Sustantivos procedentes de menciones de segmentos clave o significativos de habla («decitativos»)}

Hay sustantivos que resultan del uso metalingüístico (mención o cita) de una pieza idiomática que desempeña una función particularmente relevante en un determinado empleo discursivo. Se trata de una clase próxima a la considerada en el apartado anterior $(\$ 3.1)^{20}$. A diferencia de las unidades incluidas en $\$ 3.1$, en cuyo origen se encontraba un uso discursivo autónomo con fuerza ilocutiva (adiós, ;alto!, amén, gracias, ¡hola!, ¡viva!, etc.), las piezas lingüísticas de este grupo no derivan de usos con los que, aisladamente, se cumplan actos ilocutivos. Se trata de proferencias con cierta relevancia en el enunciado en que aparecen. Me refiero a lexemas sustantivales como ${ }^{21}$ :

19 El latinismo, hoy poco usado, abrenuncio (del lat. abrenunť̌o, de abrenuntiāre, renunciar) «interj. coloq. poco us. Usado para dar a entender que se rechaza algo» (DRAE 2001) procede de una fórmula empleada en la liturgia del bautismo. Cf. también el anglicismo tenis $(<$ tennis, al parecer del fr. ant. tenez 'tened', imperativo dirigido por el que juega a su adversario.

${ }^{20}$ De Brabanter separa esta clase de la anterior porque estima que «it is much less obvious that the items found here derive from words or phrases whose utterance in isolation carries illocutionary force» (De Brabanter 2005, p. 182). joya'.

${ }^{21}$ Otras formas: dijes f. pl. 'bravatas' (DRAE 2001; no lo registra el DEA), quizá dije 'adorno, 
considerando: m., en Derecho, en una disposición o en una sentencia, razón de las que sirven de fundamento, encabezada por la palabra considerando $(\text { DEA, s.v. })^{22}$,

debe: $\mathrm{m}$., en una cuenta corriente, columna en que se anotan las cantidades negativas (DEA, s.v.).

distingo: m. distinción, esp. sutil. Frec. en pl. y con intenc. desp. (DEA, s.v.), exhorto: (1. a pers. de sing. del pres. de indic. de exhortar, fórmula que el juez emplea en ciertos despachos) m. Der. Despacho que libra un juez a otro de igual categoría para que mande dar cumplimiento a lo que le pide (DRAE 2001; también en DEA).

resultando: gerundio de resultar, $m$. Der. Cada uno de los fundamentos de hecho enumerados en sentencias o autos judiciales, o en resoluciones gubernativas (DRAE 2001; también en DEA).

Aunque con finalidad burlesca, ha gozado de arraigo en otras épocas, a juzgar por el título de la comedia de Tirso «El castigo del penseque ${ }^{23}$ y por el refranero de Correas ${ }^{24}$, la forma penseque, en la que el indefinido pensé aglutina la conjunción completiva que; lo registran DRAE 2001 y DUE ${ }^{25}$; y no faltan testimonios en español actual:

(39) Estos son los políticos del «yo diría», parientes de aquellos estudiantes del «creíque» y el «penseque» $(A B C, 17.11 .83$; más otro testimonio de 1982, CREA).

El DRAE 2001 registra la forma pesia (contracción de pese a) como interj. poco usada, utilizada para expresar desazón o enfado (DRAE 2001).

Para la forma dizque (de dice que) el DRAE 2001 registra dos acepciones: 1. m. dicho, murmuración, reparo. Utilizado mayoritariamente en pl., y 2. adv. Am. al parecer, presuntamente (Eberenz 2004, pp. 147, 151).

\footnotetext{
22 También se documenta concluyendo como sustantivo: «Aquí las conclusiones, el concluyendo aparece como papel redactado desde donde llamar a la reflexión, a modo, eso sí, de resumen no detallado" (M. Marín, <http://www.adsis.org/img_proyectos/341/Estudio\%20completo1.pdf>). Lo registra Náñez Fernández 2006: los concluyendos.

23 Tirso de Molina, «El castigo del penseque», Doze comedias nueuas, Valencia, en casa de Pedro Patricio Mey, 1631.

${ }^{24}$ Correas registra los siguientes refranes o frases con penseque: «El pensar no es saber / $\mathrm{Al}$ que dice: pensé que, le añaden: penseque, asneque, burreque, con sus parientes» (Correas, refrán no 8108); «Pensé que era asneque y era burreque / Esto lo crecen sobre penseque» (Correas, $\mathrm{n}^{\circ}$ 18089); «Penseque, asneque, burreque con sus parientes / Añádenlo al que se excusa diciendo: Pensé que...» (Correas, $\mathrm{n}^{\circ}$ 18097); «Penseque, asneque y burreque, todos son hermanos / Trata de asno y burro al que pierde la cosa, y se excusa con Pensé que...» (Correas, $\mathrm{n}^{\circ}$ 18098); «Penséque y asnéque y burréque / Por el que pensó neciamente» (Correas, n⿳0 18099).

${ }^{25}$ DRAE 2001: penseque (De la expr. pensé que): 1. m. coloq. Error nacido de ligereza, descuido o falta de meditación. DUE: «de la frase pensé que...». No lo registra el DEA.
} 
El Diccionario panhispánico de dudas (2005) la da como vigente en «amplias zonas de América» (s.v. dizque) y añade: «También se emplea como adjetivo invariable, antepuesto siempre al sustantivo, con el sentido de presunto o pretendido». Company 2006, pp. 107-110 ha estudiado el proceso que va desde verbo de lengua (decir que) a marcador discursivo de evidencialidad (dizque 'al parecer') para expresar la incertidumbre o duda del hablante respecto a lo dicho por otra instancia.

El sustantivo masculino trágala (coloquial, m. acción por la que se obliga a alguien a aceptar algo a la fuerza, según el DEA), que forma parte de la locución adverbial a la trágala 'de manera atropellada' (DEA) puede incluirse aquí también. El origen de este nombre hay que buscarlo en el famoso pareado que cantaban los liberales a los absolutistas (los serviles) durante el trienio liberal (1820-1823):

(40) Trágala, trágala, trágala servilón / trágala, traga la Constitución ${ }^{26}$.

(41) Se les ha metido en la cabeza que, para ser gran patriota, no se necesita más que cantar el trágala a grito pelado (1820-1823, S. de Miñano, Sátiras y panfletos del Trienio Constitucional (1820-1823), ed. de Claude Morange, Madrid, CEC, 1994, p. 426).

(42) No sólo no me emplearon, sino que me cantaron el trágala (1833, M. J. de Larra, Las circunstancias, ed. de A. Pérez Vidal, Barcelona, Crítica, 2000, p. 150, CREA).

(43) Al volver a Palacio, los milicianos aclaman la Constitución y a Riego, y una voz atrevida grita en favor del Rey neto. Los chicos cantan el trágala (1876, B. Pérez Galdós, 7 de julio, Alicante, Universidad de Alicante, 2003, p. 151, CREA).

Asimismo podría citarse en este apartado la forma esque 'excusa', de la que se documentan abundantes testimonios ${ }^{27}$ :

(44) Ya no valen las excusas de siempre o los «ysis» y los «esques» (<http://www.diariosigloxxi.com/texto-diario/mostrar/36299>).

La forma sanseacabó aglutina el tratamiento san y el pronombre se al indefinido de $3^{\underline{a}}$ pers. del sing. del verbo acabar. La registran los diccionarios: sanseacabó 'interj. (col.) Expresa el final definitivo de algo. b) Puesta al final de una enumeración, subraya lo escaso de esta' (DEA, DRAE 2001). Y el sustantivo acabose (de acabó y se) 'el colmo', generalmen-

${ }_{26}$ Ó. Alzaga Villamil, I. Gutiérrez Gutiérrez y J. Rodríguez-Zapata, Derecho político español, según la Constitución de 1978, Madrid, Centro de Estudios Ramón Areces, 2001, p. 205.

${ }^{27}$ El sustantivo m. pollaque (< pues ya que...) se documenta, humorísticamente, en la lengua coloquial, para referirse al artesano al que se le puede pedir hacer un arreglo de entidad menor cuando se le contrata para otro (Pues ya que está aquí, arregle este grifo). También significa la acción misma de aprovechar la oportunidad. 
te como predicativo con ser, aglutina el enclítico se (DRAE 2001, DEA) ${ }^{28}$. Otros sustantivos: parapoco (m. y f., col.) 'persona de poco valor' (DRAE 2001, DEA); simpecado (de sin pecado [concebida], fórmula religiosa referente a la Inmaculada Concepción de la Virgen María) m. Insignia que en las procesiones sevillanas abre marcha en la sección de cofradías de la Virgen (DRAE 2001, DEA).

También pueden incluirse aquí sustantivos como pero, porqué, qué, cómo cuándo, cuánto, dónde, conque, conqué, el latinismo quid, todos ellos registrados como tales nombres en los diccionarios de la lengua:

cómo: $\mathrm{m}$. modo «Siempre precedido del artículo $e l »(\mathrm{DEA})$;

conque: (con pronunciación tónica) m. (col.) inconveniente o pega (DEA); 3. m. coloq. Condición con que se hace o se promete algo (DRAE 2001);

conqué: m. (col.) «Siempre precedido de $e l$ o de posesivo» «medios, esp. de subsistencia» (DEA). El DRAE 2001 solo registra para este sust. m., que restringe a El Salvador, la acepción de «comida con la que se acompañan las tortillas de maíz»;

cuándo: m. tiempo o momento «Precedido del artículo $e l »(\mathrm{DEA})$;

cuánto: m. cantidad «Precedido del artículo $e l »$ (DEA);

dónde: $\mathrm{m}$. lugar «Precedido del artículo $e l »$ (DEA);

pero: a diferencia del carácter átono de pero conjunción, pero nombre es tónico. El DEA registra dos acepciones de pero sustantivo: «defecto o inconveniente» y «objeción». Su plural es regular: peros;

porqué: m. causa o motivo «Gralmente. precedido del artículo el» (DEA); con frecuencia, escrito también por qué;

qué: m. naturaleza o entidad [de una cosa]. «Precedido del artículo $e l$. Cita testimonio: "Que eso de las quemaduras no es el qué, es el cuánto, decía» (Delibes, Guerras, 92). (DEA s.v. qué);

quid: (del lat. quid, qué cosa) m. esencia, punto más importante o porqué de una cosa. El quid (DRAE 2001).

No registran los diccionarios, en cambio, quién ni para qué, que poseen frecuentes usos nominales, además de la locución nominal, calco del inglés, quién es quién ${ }^{29}$ :

(45) Esa plenitud de mundo que el alma, el yo, el sujeto, el quien, el cada uno lleva como un Atlante glorioso (1976, R. Chacel, Barrio de Maravillas, Barcelona, Seix Barral, 1991, 172-173, CREA).

\footnotetext{
28 Por analogía con acabose, cf. las creaciones humorísticas continuose y empezose: «Y aún hay gente que achaca el horrendo crimen a la falta de valores de la juventud. Como diría Mafalda, esto no es el acabóse, es el continuóse del empezóse de ustedes» [sic] (I. Lozano, «El continuóse del empezóse» [sic], $A B C, 19.2 .09$, p. 78).

${ }^{29}$ Copio un testimonio: «Un quién es quién digital de la historia de España» (titular, El País.com, 3.12.08).
} 
(46) Las eternas preguntas sobre el origen y fundamento de los hechos culturales cifradas en el cuándo, cómo, dónde y porqué e incluso, si se quiere, el para qué, deben formularse constantemente (A. Beltrán Martínez, Pueblos de Aragón II, Zaragoza, Institución Fernando el Católico, 2000, p. 587, CREA, donde se documentan 34 casos más).

\section{Asimismo pueden integrarse en este grupo sustantivos o locuciones sustantivas como:}

el qué dirán: $\mathrm{m}$. la opinión de la gente; miedo al qué dirán, DEA s.v. qué; no sé cuántos: Sustituye provisionalmente al nombre, que no se puede o no se quiere precisar, de una persona o cosa, DEA; loc. sust. m. fulano (persona indeterminada), DRAE 2001;

(un) no sé qué: $\mathrm{m}$. una cosa que no se sabe explicar; se le nota un no sé qué, DEA s.v. qué; DRAE 2001;

no sé quién: pron. indefinido, alguien, DEA.

En otros casos, el segmento mencionado que dio origen al lexema nominal pudo ser la palabra (o grupo de palabras), generalmente en posición inicial, de un texto, ya sea de carácter religioso (avemaría, gloria, padrenuestro, por la señal ${ }^{30}$, yo pecador, etc. y un nutrido grupo de nombres en latín: abrenuncio, adefesio, credo, dies irae, lavabo ${ }^{31}$, magnificat, misa ${ }^{32}$, mi- $^{-}$ serere, nunc dimitis, oremus en la locución verbal perder el oremus 'perder el juicio, la cordura o la idea de lo que se va a hacer o decir', réquiem ${ }^{33}$, salve, te Deum, te igitur ${ }^{34}$, tuáutem $^{35}$; el helenismo kirie o quirie ${ }^{36}$, el hebraísmo

${ }^{30}$ En la lengua familiar de España ha tenido cierta difusión el sustantivo porla, que aglutina las dos primeras palabras de la fórmula que se recita al signarse con la cruz: «Por la señal de la santa cruz, etc.» Hay testimonios de uso: «Y ahora vamos a hacerte el porla. Momento en que se detienen todas, se persignan con la vieja fórmula del Por la señal de ... y se marchan de la habitación» (Rosa Montero, El País digital, 4.9.84); «Al solemne acto de signarse y santiguarse le llama la gente porla» (X. L. Barreiro, La Voz de Galicia, ed. digital, 30.8.07).

${ }^{31}$ Latinismo es también placebo (del latín placebo, 1. ${ }^{a}$ pers. de sing. del fut. imperf. de indic. de placere $): 1 . \mathrm{m}$. Med. Sustancia que, careciendo por sí misma de acción terapéutica, produce algún efecto curativo en el enfermo, si éste la recibe convencido de que esa sustancia posee realmente tal acción (DRAE 2001). E incluso la marca comercial sueca de vehículos Volvo.

${ }^{32}$ De Ite, missa est, independientemente de qué sea el sujeto del participio missa.

33 Acusativo de sing. del lat. requies, 'descanso' (< requiem aeternam dona eis, Domine, etc.), m. composición musical que se canta con el texto litúrgico de la misa de difuntos, o parte de él (V. misa de réquiem).

${ }^{34}$ La Prof. V. Escandell me comunica la existencia de la locución comparativa más sobado que el tegito, alusiva al aspecto que ofrece la página del misal que contiene el comienzo del canon romano, que empieza precisamente con las palabras Te igitur clementissime Pater.

35 Del lat. Tu autem, [Domine, miserere nobis], «pero Tú, [Señor, ten piedad de nosotros]», palabras con que terminan las lecciones del Breviario). 1. m. coloq. poco usado. Persona que se tiene por principal y necesaria para algo. 2. m. coloq. poco usado. Cosa que se considera precisa e importante para algún fin (DRAE 2001).

36 1. m. Invocación que se hace a Dios, al principio de la misa, tras el introito. Usado mayoritariamente en pl. echar los kiries. 1. fr. coloq. And. vomitar; llorar los kiries. 1. fr. coloq. Llorar mucho (DRAE 2001). 
aleluya), lúdico (canciones, el Porompompero de Manolo Escobar, el La la la de Massiel en el festival de Eurovisión, cf. supra Aserejé, etc.), político (Cara al sol), o de otro carácter (Soy minero, Cuéntame, Gaudeamus, etc.). Cuando identifican sólo un texto determinado constituyen nombres propios: padrenuestro, avemaría, etc. Pero otras veces, como la voz credo, que aparece en locuciones -en un credo.1. loc. adv. coloq. En breve espacio de tiempo (DRAE, DEA) - son nombres comunes («conjunto de doctrinas comunes a una colectividad», DRAE 2001).

Es frecuente que la denominación de varios juegos se realice mediante una expresión significativa de su materialización lingüística: veoveo; adivina quién te dio; arráncate, nabo; arrepásate acá, compadre; salga la parida; salta tú y dámela tú; sopla, vivo te lo doy; tú la llevas (o tienes), etcétera:

(47) En la cama, seguían a veces jugando al veoveo, o a enumerar por orden alfabético nombres de flores y animales. (L. Landero, Juegos de la edad tardía, Barcelona, Tusquets, 1993; más 3 testimonios más del mismo autor, y otro de Lorenzo Silva).

Casos extremos de segmentos mencionados o citados devenidos lexemas nominales son el sufijo -ismo, registrado como tal lexema ismo m. 'tendencia o doctrina artística, literaria o filosófica'. «Frec. con intención desp., aludiendo a su carácter pasajero o minoritario» (DEA). (cfr. ing -teen > teenager); y la forma tico, tica (adj. coloq. costarricense, aplicado a persona, utilizado también como singular, debido a que los hablantes de Costa Rica no usan el sufijo -ito, sino -ico, tras -t-: calentico, no calentito (cf. DRAE 2001, DEA).

Constituyen creaciones metonímicas lexicalizadas formas como:

$c h e^{3}$ : m. y f., col., humoríst. valenciano; $c h e^{2}$ : interj. que se usa para llamar la atención de una persona o para protestar ante lo que se ha dicho (DEA, que cita testimonio; probablemente se trate del marcador conversacional enfocador de la alteridad chico);

che: en el español de Chile, argentino (Oroz 1966, p. 476); en Argentina, ;che! interj. coloq. Se usa, con valor apelativo, al pedirle o preguntarle algo a una persona a la que generalmente uno tutea (Chuchuy 2000, s.v.) ${ }^{37}$.

cuate (del nahua): 1. adj. Guat., Hond. y Méx. camarada, amigo íntimo. Usado tb. como sustantivo: 2. adj. Méx. mellizo (nacido de un mismo parto). Usado tb. como sustantivo; 3. adj. Méx. igual o semejante (DRAE 2001) ${ }^{38}$. maño, ña (adj. coloq.): aragonés (natural de Aragón). Usado tb. como sustantivo (DRAE). (Martín Zorraquino 2002).

${ }^{37}$ Ya en el siglo xix, che es interjección muy usada en Argentina, equivalente a ¡hola!, como lo refleja el Diccionario rioplatense razonado de Granada (1889).

${ }^{38}$ En un ámbito diatópico preciso se documenta coño como sustantivo m. despect. Chile «español (natural de España)» (DRAE 2001), por la frecuencia con que los españoles emiten esa voz como interjección. También en Chile, coño m. fam. modo de hablar el español característico de las gentes de España (F. Morales Pettorino, dir., Diccionario ejemplificado de chilenismos, II, Academia Superior de Ciencias Pedagógicas de Valparaíso, 1985). 
No faltan creaciones efímeras de sustantivos basadas en metonimias:

(48) Los «mireusted» [título de columna periodística] [...] Hasta le pillo el punto a la visión fugaz de contertulios [...] con apariencia, gestualidad, discurso e ideología inequívocos que empiezan su indignada y concienciada soflama con el clónico: «Mire usted» (C. Boyero, El País, 27.6.09, «Vida y Artes», p. 69).

El segmento mencionado que da lugar a un sustantivo puede ser onomatopeya de un sonido o ruido, humano, animal o de la naturaleza inanimada. El Diccionario de voces naturales de García de Diego registra abundantes casos. De los diccionarios DRAE 2001 y DEA se pueden extraer, por ejemplo, voces como:

achís (DRAE 2001. DEA sólo registra el valor de interj.); $b e^{2}$ (DRAE 2001; no figura en DEA); bla-bla-bla o blablablá (DEA); bu (DRAE 2001. No figura en DEA); chinchin ${ }^{2}$ (DRAE 2001. También en el DEA como m. despect.; es una expresión que se dice al brindar); chunda (DEA. No en DRAE 2001); clic (DRAE, avance de la $23^{\underline{a}}$ ed.; «frecuentemente se sustantiva como n. m.» (DEA); cuco (DRAE 2001. Tb. DEA); cucú -DRAE 2001. En DEA, m. (reg.) 'cuco (ave)'; frufrú (DRAE 2001 y DEA); gluglú (DRAE 2001); guau (DRAE 2001); DEA: en el lenguaje infantil, guauguau 'perro'; marramao (DRAE 2001); miau -DRAE 2001; DEA: m. (infantil) 'gato (animal) '-; $m u^{1}$ (DRAE 2001, DEA); $p i^{1}{ }^{1}$ (DRAE 2001; DEA: «frecuentemente se sustantiva»; m. col. 'anhelo o ilusión'); quiquiriquí (DRAE 2001; DEA «frecuentemente se sustantiva como n. m.»; m. col. "mechón de pelo que se destaca sobre la cabeza'); tamtan (DRAE 2001; DEA: tam-tam m. 'tambor africano'); tantán: (de or. onomat.). m. 'campana de a bordo' (DRAE 2001); tantarantán (DRAE 2001; DEA); tictac (DRAE 2001, DEA); tilín (DRAE 2001, DEA); tintín (DRAE 2001, DEA); tintirintín (DRAE 2001); tiroriro (DRAE 2001); tolón (DEA); yaacabó (DRAE 2001).

También pueden citarse aquí los sustantivos deverbales de las formaciones onomatopéyicas en -ear (o-ar) (cf. infra), como arrullo, balido, berrea, cacareo, carraspeo, cuchicheo, ronroneo, siseo, tintineo, etcétera.

En el lenguaje infantil abundan los testimonios de uso de las onomatopeyas como sustantivos:

(49) Tiene 3 años y les llama [a los cencerros] los tolón-tolón. Lo hace desde que les vio desfilar por primera vez en el olentzero de Pamplona (Diario de Navarra, 26.1.09, p. 72).

\subsection{Otros nombres decitativos («deautónimos») provienen de sustitutos oracionales y adverbios}

Se trata de formas como si 'aceptación o asentimiento' (DEA) y no 'negativa' (DEA) ${ }^{39}$, cuyas acepciones nominales figuran en el diccionario.

39 El DRAE 2001, a diferencia del DEA, no registra la correspondiente acepción nominal para no. 
También figuran en los diccionarios las acepciones, como nombres, de los adverbios deícticos de anclaje discursivo ayer (m. 'tiempo pasado', DRAE 2001), hoy (no DRAE; m. 'el presente', DEA), ahora (no DRAE; m 'tiempo o momento presente', DEA), mañana (m. 'tiempo futuro más o menos próximo', DRAE 2001), aquí (no DRAE; m. 'lugar determinado', DEA). El DEA registra la loc. adv. hic et nunc, así como aqui y ahora ${ }^{40}$.

Otras piezas, como nunca, jamás (jamás de los jamases, DEA), quizás, acaso, ojalá, tal vez, etc. no figuran en los diccionarios como nombres, aunque su uso como tales es frecuente, con la correspondiente formación de plural:

(50) Tal vez piense que toda esta prueba no es más que un prólogo; que fui y hablé con ella, que le traigo un mensaje, un arrepentimiento, un pedido de perdón, un nunca, algún jamás (1979, J. C. Onetti, Dejemos hablar al viento, Madrid, Mondadori, 1991, 159, CREA).

(51) Contaré lo que he sabido que ocurrió [...]. No dejaré que crezcan los quizás, los acasos, ni diré que hay momentos ocultos (B. Gopegui, Lo real, Novela, Anagrama, Barcelona, 2001 CREA).

(52) Este adiós no maquilla un hasta luego, este nunca no esconde un ojalá, estas cenizas no juegan con fuego, este ciego no mira para atrás (letra de una canción de J. Sabina, en Espéculo. Revista de estudios literarios, 06/2003, CREA).

(53) Sin el sufrimiento de un quizá y un tal vez (1992, J. Marías, Corazón tan blanco, Barcelona, Anagrama, 1994, 221, CREA).

La forma ojalá, incluso, ha desarrollado derivados adjetivos de carácter metonímico: ojalatero-a ('persona que profiere muchos ojalá; mística ojalatera 'actitud irrealista, ilusa') y ojalatería ('cualidad de la persona ojalatera'):

(54) Era ojalatero, pero no de profesión, por eso sin hache. Era de esos que estaban todo el tiempo ;Ojalá que fulano haga tal cosa! [...] Para él todo era ojalá esto y ojalá aquello [...] Casi siempre se salía con su ojalatería. (R. Cardona, Doña Carmen y su barrio, San José de Costa Rica, EUNED, 2000, 1).

(55) Es lo que repetidas veces he llamado la mística ojalatera, hecha de ensueños vanos y de falsos idealismos: ¡ojalá no me hubiera casado, ojalá no tuviera esa profesión, ojalá tuviera más salud, o menos años, o más tiempo! (Conversaciones con Mons. Escrivá de Balaguer, Madrid, Rialp, 21를 ed., 2003, § 88).

\footnotetext{
40 «No ha sido capaz de poner su mensaje político en plena sintonía con el aqui y ahora de este fin de siglo» (El Mundo, Madrid, 25.5. 95, CREA).
} 


\subsection{Sustantivos y locuciones nominales de (aparente) estructura oracional y dudoso origen metadiscursivo}

La lengua española cuenta con un conjunto de sustantivos como bienmesabe, correveidile, correverás, hazmerreir, metomentodo, miramelindos, nomeolvides, quitaipón, sabelotodo, tentemozo, tentempié, tentetieso, vaivén, zampalopresto, etc. García-Page los denomina «compuestos gráficos de aparente estructura oracional» (García-Page 2008, p. 110). Sólo un estudio diacrónico sabría determinar si, en su origen, pudieron obedecer a usos metalingüísticos o si se deben a creaciones más o menos ingeniosas basadas en esquemas combinatorios recurrentes.

Por otra parte, existe también un conjunto de «locuciones nominales binómicas» (García-Page 2008, p. 98), como dimes y diretes, ordeno y mando, suma y sigue, ten con ten, tira y afloja, toma y daca, etc., cuyo origen metalingüístico habrá que indagar. Es creación reciente, aunque difundido, el nombre voy y vengo 'autobús que traslada a los jóvenes a las fiestas, para prevenir posibles accidentes de tráfico’.

\subsection{Deautónimos de pronombres}

También el uso metalingüístico de los pronombres ha incidido en el léxico del español, como, por lo demás, ha ocurrido en otras lenguas ${ }^{41}$. Los diccionarios registran yo (además del latinismo ego, DRAE 2001) ${ }^{42}$ y ello como sustantivos. E incluso derivados de yo como yoidad (f. Fil. 'condición de ser yo', DRAE 2001). El derivado yoísmo se documenta con abundancia:

(56) La presencia de Galíndez se hacía cada vez más intolerable por su vanidad desbridada, por su yoísmo narcisista (1990, M. Vázquez Montalbán, Galindez, Barcelona, Seix Barral, 1993, p. 242, CREA; más 6 testimonios).

La forma tú como sustantivo, en cambio, no la registran el DEA ni el DRAE 2001. Sí registra, sin embargo, el DEA la loc. n. m. tú y yo ('conjunto formado por un mantel pequeño y dos servilletas a juego'; asimismo, aunque no lo registran DRAE 2001 y DEA, «asiento en que los ocupantes se colocan en dirección opuesta»). También las loc. v. hablar, tratar o llamar de tú 'emplear el pronombre tú, y no usted, para referirse al interlocutor'; 'tratar en un plano de igualdad', 'conocer de cerca o a fondo [una $\operatorname{cosa}(\mathrm{CD})]^{\prime}$ (DEA).

\footnotetext{
${ }^{41}$ «Almost all English personal pronouns have nominalised uses, many of wich are recorded in dictionaries» (De Brabanter 2005, p. 183).

42 1. m. Psicol. En el psicoanálisis de Freud, instancia psíquica que se reconoce como yo, parcialmente consciente, que controla la motilidad y media entre los instintos del ello, los ideales del superyó y la realidad del mundo exterior. 2. m. coloq. Exceso de autoestima (DRAE 2001).
} 
Sin embargo, es fácil documentar empleos nominales de tú, usted, vos, nosotros, vosotros, ellos, como ilustran los siguientes testimonios:

- tú:

(57) Entre que apaleasen a Silvia o te apaleasen a ti, creo que elegiste lo primero. Entre el yo y el tú, elegiste el yo. (1986, A. Buero Vallejo, CREA).

- usted: no lo registran el DEA ni el DRAE como nombre decitativo; el DEA (no el DRAE) recoge las loc. v. hablar, tratar o llamar de usted:

(58) Los entrevistadores llamarían de usted a sus clientes, los entrevistados eran libres, claro está, de emplear el tú o el usted (La Razón digital, 22.4.04, CREA).

(59) Entonces no se descarta el usted, ¿̇verdad? El usted le da más respeto a una conversación (oral, Encuesta 74, Paraguay, CREA).

- vos:

(60) Entre dominicanos sobre todo, gente de Centroamérica, ¿no?, que usa el vos. (oral, encuesta 118, Carlos Villagrá Marsal, Paraguay, CREA).

(61) Por supuesto tampoco se me va a ocurrir usar solamente el vos en mis clases, salvo como introducción dialectal, donde lo presento junto con el vosotros (1999 Correo electrónico, España, CREA).

- él:

(62) Es un músico aristocrático y un compositor para minorías, que escribió para ese él que supo renovar, enriquecer y transformar (1990, J. V. Melo, CREA).

(63) Pero ¿quién asignaba esos recursos? ¿Quién era ese él al que acusaba tantas veces? (1999, J. Volpi, CREA).

- nosotros, ellos:

(64) Otra vez el nosotros y ellos, el doble patrón de conducta, la esquizofrenia del split mind (El País, España, 09.9.77, CREA).

- vosotros:

(65) Si te molesta el vosotros, [...] protesta a tu gobierno. Por cierto, no sé si sabrás que, en España, ese famoso vosotros se utiliza sólo de Castilla para arriba. Tanto los andaluces como los canarios y los extremeños utilizan también el ustedes (Correo electrónico 1999, España, CREA).

Las etiquetas metalingüísticas leísmo, laísmo, loísmo, queísmo, dequeísmo, quesuismo, y los correspondientes adjetivos en -ista, así como tuteo, voseo, 
ustedeo $^{43}$, derivan de los usos citativos de sus bases (le, la, lo, que, de que, que su, tú, te, vos, usted). En estos últimos casos, a través de los verbos $t u$ tear, vosear, ust(ed)ear.

Aquí cabe citar el sustantivo aquelm. coloq., «voz que se emplea para expresar una cualidad que no se quiere o no se acierta a decir. Se toma frecuentemente por gracia, donaire o atractivo". Juana tiene mucho aquel. (DRAE y DEA).

\subsection{Verbos derivados de menciones: delocutivos y decitativos}

a) Un conjunto de verbos representa la contrapartida verbal de los sustantivos clasificados como provenientes de expresiones con las que se ejecutan actos ilocutivos $(\S 1)$. Serían, pues, verbos delocutivos. El significado de estos verbos puede captarse, según De Brabanter, a través de la fórmula to say: "X», en donde say significa 'to perform an illocutionary act' $\mathrm{y}$ «X» representa el CD mención de la palabra o fórmula con que se realiza el acto discursivo. Son ejemplos en inglés to hail, to encore, to okay, to yes, to welcome. Corresponderían, en español, a formaciones verbales en -ear (la mayoría) -todas ellas registradas en el DRAE (bastantes también en el DEA)- como arrear, ayear, azuzar, bisar, chistar, guayar, holear, jalear, jesusear, olear, oxear (u osear), pordiosear, señorear, vitorear, zapear, etc., de variada vigencia cronológica y diafásica:

arrear $^{1}$ (de arre) (DRAE 2001 y tb. DEA); ayear (DRAE 2001, DEA); azuzar (de la interj. sus) (DRAE 2001, DEA); bisar tr. 'repetir [algo, esp. una actuación]', y 'repetir [un número], poniendo la segunda vez la palabra bis' (DEA; DRAE 2001, de bis); chistar (DRAE 2001); guayar (de iguay!) intr. ant. 'llorar, lamentarse' (DRAE 2001); holear intr. 'usar repetidamente la voz hola' (DRAE 2001; no en DEA ni CREA; para Anscombre 1985, verbo delocutivo); jalear (de ;hala!) (DRAE 2001); jesusear (col.) intr. 'repetir muchas veces la palabra Jesús'; 2. 'musitar oraciones' (DEA, DRAE 2001); olear (de ole, García de Diego 1968, p. 128 'llamar a otro'); oxear (de ox) (DRAE 2001, tb. en el DEA) y osear, en ambos; pordiosear (de por Dios) (DRAE 2001, DEA; para Anscombre 1985, verbo delocutivo; registran también los diccionarios pordiosero 'mendigo', pordioseo, pordiosería; señorear tr. coloq. 'dar a alguien repetidas veces e importunamente el tratamiento de señor' (DRAE 2001; esta acepción no la registra el DEA); vitorear tr. 'aplaudir o aclamar con vítores [con la palabra víctor o vítor] a una persona o acción' (DRAE 2001; DEA); zapear 'espantar al gato con la voz zape' (DRAE 2001; para Anscombre 1985, verbo delocutivo).

El caso de bisbisear o bisbisar -tr. coloq. musitar DRAE 2001; también bisbiseo: 1. m. acción de bisbisar (de bisbís)- y de otros muchos verbos

\footnotetext{
${ }^{43} \mathrm{Si}$ bien ustedeo no figura en los diccionarios, abundan los testimonios de uso. P. ej., el artículo «Tuteo y ustedeo en los Andes de Venezuela», de F. Freites Barros, Interlingüistica, 16, 2006, pp. 1-10).
} 
basados en onomatopeyas resulta diferente, ya que con tales sonidos onomatopéyicos no se realizan actos ilocutivos (Conte 1987, p. 50). Así, tenemos, por ejemplo: ajear (intr. dicho de una perdiz: repetir, como quejándose, aj, aj, aj, cuando se ve acosada, DRAE 2001), arrullar, balar, berrear, cacarear, carraspear, clicar 'hacer clic', croar, cuchichear, mugir, ronronear, sisear, tictaquear (DEA intr. 'hacer tictac [un reloj]'), tintinar o tintinear, trisar (intr. dicho de una golondrina o de otros pájaros: cantar o chirriar, DRAE 2001), etc., ${ }^{44}$ o la locución verbal hacer tilín [a alguien una persona o cosa] (DEA, col. gustar[le]) (cf. supra los sustantivos deverbales correspondientes: arrullo, balido, berrea, cacareo, etcétera).

El verbo hurrar ('aplaudir o aclamar con hurras') no aparece registrado en los diccionarios, pero he documentado usos que testimonian la posibilidad ofrecida por el sistema:

(66) Ahora bebamos nomás con buen hurrar / Por Buenos Aires que nos dio su mejor dolár [sic] (traducción del panfleto inglés «Dollars of Buenos Ayres» a cargo de J. Argentino) (<http://invasionesinglesas.blogspot.com $>$ ).

En Arniches aparece el verbo hurraar (M. Seco, Arniches y el habla de Madrid, Barcelona, Alfaguara, 1970, pp. 98 y 172):

(67) LUCAS: iHurra por el Valentino de Embajadores!

LOS TRES: ¡HURra!

CATAlino: iHurra por Sidoro Perales, Mediacapa!

LOS TRES: ¡HUrra!

SIDORO: (Avanzando) ¡Gracias, queridos cólegas! Agradecido a los encomios. Y después de los gritos con que me habéis $h u$ rraao, tomar asiento en las poltronas a la vista.

(C. Arniches, Teatro completo, ed. de E. M. del Portillo, Madrid, Aguilar, 1948, Vol. III, p. 643).

b) Un segundo grupo de verbos estaría constituido por aquellos que incorporan, como elementos componentes de verbos, menciones de pronombres (tú, te, vos, usted) o nombres (o sonidos) de letras ([e]se, ce): me refiero a tutear, vosear, uste(de)ar, cecear, sesear, ensimismar, etc. Todos, salvo uste(de)ar, están incluidos en los diccionarios. El verbo uste(de)ar, sin embargo, presenta abundantes testimonios de uso:

(68) Le dije que dejara de ustearme, que no era tan viejo, y que a partir de ahora nos tuteáramos (M. Vargas Llosa, Travesuras de la niña mala, Madrid, Alfaguara, 2006, p. 302).

(69) ¿Por qué ustea a los jugadores? (El País, 1.9.91, p. 32, apud Rainer 1993, p. 463).

${ }^{44}$ Rainer 1993, p. 463 cita cloquear, tararear, tintinear. 
(70) El problema recide [sic] en que somos varios los que tuteamos como forma natural de hablar, y muchos otros que están acostumbrados a «ustedear» como forma natural (<http://osdir.com/ml/php.sabrosus.user $/ 2006-09 / \mathrm{msg} 00025 . \mathrm{html}>)$.

Del neologismo eñear proporciona un testimonio F. Rainer:

(71) Continuaremos encizañando la lengua eñeando a nuestro antojo ( $E l$ Pais, 10.5.91, 16, apud Rainer 1993, p. 463).

En este epígrafe hay que citar asimismo las locuciones verbales tratar de tú, tratar de usted y tratar de vos.

La diferencia de este segundo grupo de verbos (3.6.a) con respecto a los anteriores (3.6.a), radica en que los del grupo b) no significan propiamente la realización de acto ilocutivo (espantar, aplaudir, quejarse, llamar la atención, etc.) que contenían los de § 3.6.a). No son, pues, delocutivos, sino, en terminología de Anscombre 1985, «citativos» (salvo cecear y sesear, que tampoco son citativos).

\subsection{Locuciones adjetivas y adverbiales}

Como he dicho antes a propósito de los sustantivos y las locuciones de aparente estructura oracional y dudoso origen metadiscursivo (\$3.4), en español existe un considerable conjunto de locuciones adjetivas y adverbiales, registradas en los diccionarios, en cuyo origen, a juzgar por la forma en que han quedado lexicalizadas, pudo haber una mención (o «autonimia»). Solo el estudio diacrónico podrá dar cuenta de lo ocurrido. Me refiero a locuciones adjetivas como: de aqui te espero, (mujer) de digo y hago, de mírame y no me toques, de no te menees (o de agárrate y no te menees), de ordeno y mando, de padre y muy señor mio, de quita y pon, de rompe y rasga, (casa) de tócame Roque, (estar) de toma pan y moja (para Gá-Page, de toma pan y moja es una locución adjetiva, 2008, p. 118), etc. Y a locuciones adverbiales como: a la trágala, por un quítame allá esas pajas, $n+y$ tente tieso (o tentetieso), etcétera.

En estas otras locuciones adverbiales se incluye un segmento mencionado: en un (decir) Jesús, en un (decir) amén.

\section{FINAL}

Con la exposición -necesariamente sumaria- que acabo de hacer, he tratado de poner de relieve parte del impacto que el metalenguaje de discurso ha dejado en la lengua española. Según se habrá podido apreciar, no se trata sólo de algún que otro verbo delocutivo marginal, 
como tímidamente se advierte en algún tratado de formación de palabras del español. El procedimiento, que se encuentra vivo y vigente en la actualidad, alcanza a sustantivos, verbos, adjetivos y adverbios. Reclama un estudio diacrónico, que en parte espero que se esté realizando en el ámbito de las investigaciones sobre tradiciones textuales, lo que servirá para completar y enriquecer los diccionarios etimológicos, así como los diccionarios generales, que, por cierto, tratan de manera bastante irregular y asistemática, errática incluso (especialmente el DRAE), las creaciones léxicas procedentes del metalenguaje de discurso ${ }^{45}$.

\section{REFERENCIAS BIBLIOGRÁFICAS}

Anscombre, J. C. (1982): «Un essai de caractérisation de certaines locutions verbales», Recherches linguistiques 10, pp. 5-37.

—, (1985): «De l'énonciation au lexique: mention, citativité, délocutivité», Langage 80, pp. 9-34.

AZnÁrez MAuleón, M. (2006): La fraseología metalingüística con verbos de lengua en español actual, Fráncfort, Peter Lang.

—, y GonZÁlez RuIZ, R. (2005): «Aproximación desde el NSM a la semántica y pragmática de algunas expresiones de sinceridad en español actual», en Casado Velarde, M., González Ruiz, R. y Loureda Lamas, Ó. (eds.), Estudios sobre lo metalingüistico en español, Fráncfort, Peter Lang, pp. 119-145.

—, (2006): «Semántica y pragmática de algunas expresiones de sinceridad en español actual», en Casado Velarde, M., González Ruiz, R. y Romero Gualda, M. ㅁ V. (eds.), Análisis del discurso: lengua, cultura, valores, Vol. I, Madrid, Arco/Libros, pp. 1211-1227.

Benveniste, É. (1974): «Los verbos delocutivos», Problemas de lingüistica general, $4^{\underline{a}}$ ed., Vol. I, Madrid, Siglo XXI, pp. 198-206.

Briz Gómez, A. (1998): El español coloquial en la conversación. Esbozo de pragmagramática, Barcelona, Ariel.

Casado Velarde, M. (1996): «Notas sobre la historia de los marcadores textuales de explicación es decir y o sea», Scripta Philologica in memoriam Manuel Taboada Cid, vol. I, pp. 321-328.

—, (2008a): «La polifonía discursiva según el metalenguaje del español», en Álvarez Tejedor, A., Bueno García, A., Hurtado González, S. y Mendizábal de la Cruz, N. (eds.), Lengua viva. Estudios ofrecidos a César Hernández Alonso, Valladolid, Universidad y Diputación, pp. 643-657.

Casado Velarde, M.; González Ruiz, R. y Loureda lamas, Ó. (eds.) (2005): Estudios sobre lo metalingüistico (en español), Fráncfort, Peter Lang.

CAstillo PeÑa, C. (1998): «Función metalingüística, metalenguaje y autonimia», Lexis 22, 2, pp. 243-266.

\footnotetext{
45 Agradezco a Óscar Loreda Lamas y Ramón González Ruiz la lectura del original de este artículo y sus sugerencias; y a Dámaso Izquierdo Alegría, sus numerosos testimonios de «deautónimos» y su inestimable ayuda en el proceso de edición.
} 
—, (2001): «Contribución a un estudio diacrónico del sistema metalingüístico en las gramáticas del español», en Maquieira, M. y González, M.름. (eds.), Actas del III Congreso de la Sociedad Española de Historiografía Lingüistica, Madrid, Arco/Libros, pp. 293-301.

—, (2005): «La gramática de las unidades autónimas del español», en Casado Velarde, M., González Ruiz, R. y Loureda Lamas, Ó. (eds.), pp. 273-292.

Chuchuy, C. (2000): Diccionario del español de Argentina, Madrid, Gredos.

Colombat, B. y Savelli, M. (2000): Métalangage et terminologie linguistique. Actes du colloque internationale de Grenoble, Lovaina, Peeters.

Company Company, C. (2006): «Subjectification of verbs into discourse markers: semantic-pragmatic change only?», en Cornillie, B. (ed.), Topics in subjectification and modalization, número monográfico de Belgian Journal of Linguistics 20, pp. 97-121.

ConTe, M. - -E. (1984): «Delocutivité, performativité, contre-performativité», en Servat, G. (ed.), É. Benveniste aujourd'hui (Actes du Colloque International du CNRS, Tours, 1983), Vol. I, París, Société pour l'information grammaticale, pp. 65-76.

—, (1987): «Semiotica dell'enunciazione», Paradigmi 5, 13, pp. 49-63.

Corpas Pastor, G. (1996): Manual de fraseología española, Madrid, Gredos.

Coseriu, E. (1973): Teoría del lenguaje y lingüistica general, $3^{\underline{a}}$ ed., Madrid, Gredos.

—, (1977): Principios de semántica estructural, Madrid, Gredos.

—, (1981): Lecciones de lingüistica general, Madrid, Gredos.

—, (1987): Gramática, semántica, universales, 2a ed., Madrid, Gredos,

—, (1998): «La semántica estructural en España», Analecta Malacitana 32, 2, pp. 455-482.

-, (2007): Lingüistica del texto. Introducción a la hermenéutica del sentido, ed. de Óscar Loureda, Madrid, Arco/Libros.

-, (en prensa): Teoría lingüistica del nombre propio, edición a cargo de Kabatek, J. y Bello Rivas, M. ${ }^{\mathrm{a}} \mathrm{X}$.

De Brabanter, P. (2005): «The impact of autonymy on the lexicon», Word 56, 2, pp. 171-200.

DIMTER, M. (1981): Textklassenkonzepte heutiger Alltagssprache: Kommunikationssituation, Textfunktion, Textinhalt als Kategorien alltagssprachlicher Textklassifikation, Tubinga, Niemeyer.

Ducrot, O. (1986): «Pragmatique linguistique II: essai d'application: mais -les allusions à l'énonciation- délocutifs, performatifs, discours indirect», en Parret, H. (ed.), Le langage en contexte. Etudes philosophiques et linguistiques de pragmatique, Ámsterdam, John Benjamins, pp. 489-575.

Ducrot, O. (1986): El decir y lo dicho: polifonía de la enunciación, traducción de Agoff, I., Barcelona, Paidós.

Ducrot, O. y SCHAEFFER, J. M. (1995): Nouveau dictionnaire encyclopédique des sciences du langage, París, Seuil.

EBERENZ, R. (2004): «Dizque: antecedentes medievales de un arcaísmo afortunado», Lexis 28, 1-2, pp. 139-156.

Escobedo Rodríguez, A. (1992): El campo semántico hablar en español, Granada, Universidad de Granada. 
FERNÁNDEZ BERNÁRDEZ, C. (2002): Expresiones metalingüísticas con decir, La Coruña, Universidad de La Coruña.

—, (2005): «Fraseología metalingüística con decir. Análisis de algunas unidades que expresan acuerdo intensificado», en Casado Velarde, M., González Ruiz, R. y Loureda Lamas, Ó. (eds.), pp. 119-145.

GARCÉs Gómez, M. P. (2008): La organización del discurso: marcadores de ordenación y de reformulación. Madrid/Fráncfort, Iberoamericana/Vervuert.

García de Diego, V. (1968): Diccionario de voces naturales, Madrid, Aguilar.

García-Page, M. (2008): Introducción a la fraseología española. Estudio de las locuciones, Barcelona, Anthropos.

González Ruiz, R. (2000): «Felicidades, sinceramente, don Antonio. A propósito de los adverbios de enunciación», RILCE 16, 2, pp. 289-324.

—, y LOUREDA Lamas, Ó. (2005): «Algunos estudios recientes sobre lo metalingüístico en español», Verba 32, pp. 351-369.

GranadA, D. (1998): Diccionario rioplatense razonado, Madrid, Arco/Libros.

Gutiérrez OrdóÑez, S. (1997): «Del uso metalingüístico», Principios de sintaxis funcional, Madrid, Arco/Libros, pp. 381-393.

Hjelmslev, L. (1971): Prolegómenos a una teoría del lenguaje, versión española de Díaz de Liaño, J. L., Madrid, Gredos.

JESPERSEN, O. (1954): A modern English grammar on historical principles, Vol. II, Londres, G. Allen \& Unwin.

KABATEK, J. (2000): Os falantes como lingüistas. Tradición, innovación e interferencias no galego actual, Vigo, Xerais.

—, (2004): «Algunas reflexiones sobre las tradiciones discursivas», texto disponible en: <www.kabatek.de/discurso >

LARA, L. F. (dir.) (1996): Diccionario del español usual en México, México, El Colegio de México.

-, (2001): Ensayos de teoría semántica, México, El Colegio de México.

—, (2002): «Autonimia, mención y sus consecuencias para el lenguaje lexicográfico», Lengua y diccionarios. Estudios ofrecidos a Manuel Seco, reunidos por Álvarez de Miranda, P. y Polo, J., Madrid, Arco/Libros, pp. 151-159.

LOUREDA LAMAS, Ó. (1999): «Los juicios de valoración de los discursos en el español actual. Materiales para el estudio de la lingüística implícita en la lengua», LEA 22, 2, pp. 207-220.

—, (2000): «Los contenidos de los juicios de valoración extralingüística de los discursos», en Martínez, M. y otros (eds.), Cien años de investigación semántica, Vol. I, Madrid, Eds. clásicas, pp. 627-638.

—, (2001): «Del metalenguaje y sus tipos (con especial referencia a los modos de significar)», Quaderni di Semantica 22, 2, pp. 287-333.

-, (2003a): Los nombres de los tipos de texto. El campo léxico lo que se dice en el español actual, Pamplona, EunSA.

—, (2003b): «El metalenguaje de la lengua y los tipos de discurso. El campo léxico de los actos de habla», en Muñoz Núñez, M. ${ }^{a}$ D., Rodríguez-Piñero, A. I., Fernández Smith, G. y Benítez Soto, V. (eds.), Actas del IV Congreso de Lingüistica General, Vol. III, Cádiz, Universidad y Universidad de Alcalá, pp. 1653-1661. 
—, (2005): «La estructura del campo léxico lo que se dice en el español actual», en Casado Velarde, M., González Ruiz, R. y Loureda Lamas, Ó. (eds.), pp. 191-210.

—, (2006): «Tesis sobre el uso metalingüístico del lenguaje primario», en González Ruiz, R. y otros (eds.), Discurso, lengua y metalenguaje. Balance y perspectivas, Hamburgo, Buske, pp. 139-153.

—, (2007): «Zur Frage der Historizität von Texten», Romanistisches Jahrbuch 58, pp. 29-50.

—, (en prensa): «De la función metalingüística al metalenguaje: los estudios sobre el metalenguaje en la lingüística actual», Cancellier, A. y otros (eds.), Atti del XXII Convegno Aispi, Madrid, Instituto Cervantes/Associazione Ispanisti Italiani.

Maldonado, C. (1999): «Discurso directo y discurso indirecto», en Bosque, I. y Demonte, V., pp. 3549-3595.

MANERo Richard, E. (2005): Aproximación a un estudio del refrán. El refranero espanol de contenido metalingüistico, Pamplona, Universidad de Navarra.

Martín ZorraQuino, M. A A. (2002): «Sobre las formas maño(s), maña(s), ¡maño! y derivados en el español hablado en Aragón», en Echenique, Mํㅜ T. y Sánchez, J. (eds.), Actas del V Congreso Internacional de Historia de la Lengua Espanola, Vol. II, Madrid, Gredos, pp. 1553-1569.

Moliner, M.․ㅡ (1998): Diccionario de uso del español, (DUE), 2ª ed., Madrid, Gredos,

Olza Moreno, I. y GonzÁlez Ruiz, R. (2008): «Fraseología metafórica de contenido metalingüístico en español: aproximación a las unidades basadas en el plano gráfico», en Álvarez de la Granja, M.a (ed.), Lenguaje figurado y motivación. Una perspectiva desde la fraseología, Fráncfort, Peter Lang, pp. 221-238.

Olza Moreno, I. (en prensa): Aspectos de la semántica de las unidades fraseológicas. La fraseología semántica metalingüistica del español, tesis doctoral.

Oroz, R. (1966): La lengua castellana en Chile, Santiago de Chile, Editorial Universitaria.

Porto Dapena, J. Á. (1999-2000): «Metalenguaje y lexicografía», Revista de Lexicografia 6, pp. 127-151.

—, (2000-2001): «Las letras como entradas del diccionario», Revista de Lexicografía 7, pp. 125-154.

RAINER, F. (1993): Spanische Wortbildungslehre, Tubinga, Niemeyer.

Rey-Debove, J. (1978): Le métalangage, 2a ed., París, Armand Colin.

RICHARD, R. (coord.) (2006): Diccionario de hispanoamericanismos, $3^{\mathrm{a}}$ ed., Madrid, Cátedra.

Romero Gualda, M. ․ V. (1980): «Hacia una tipología del neologismo literario», Anales de la Universidad de Murcia 37, 4, pp. 145-154.

SEco, M.; ANDrÉs, O. y RAmos, G. (1999): Diccionario de uso del español, (DEA), Madrid, Aguilar.

SIRDAR-ISKANDAR, C. (1989): «Voyons!», Cahiers de Linguistique Française 11, pp. 111130.

Wierzbicka, A. (1987): English speech act verbs. A semantic dictionary, Sidney, Academic Press. 